\title{
Chronic Microcystin-LR Exposure Induces Hepatocarcinogenesis via Increased Gankyrin in Vitro and in Vivo
}

\author{
${\text { Lixiong He } \mathrm{H}^{\mathrm{a}} \text { Yujing Huang }{ }^{\mathrm{a}} \text { Qiaonan Guo }{ }^{\mathrm{b}} \quad \text { Hui Zeng }}^{\mathrm{a}} \quad$ Chuanfen Zheng $^{\mathrm{a}}$ \\ Jia Wang ${ }^{a}$ Ji-an Chenc Lingqiao Wang ${ }^{a}$ Weiqun Shu ${ }^{a}$
}

aDepartment of Environmental Hygiene, College of Preventive Medicine, Army Medical University, Third Military Medical University, Chongqing, bDepartment of Pathology, Xinqiao Hospital, Army Medical University, Third Military Medical University, Chongqing, 'Department of Health Education, College of Preventive Medicine, Army Medical University, Third Military Medical University, Chongqing, China

\section{Key Words}

Microcystin-LR • Gankyrin • Malignant transformation • Oncogene $•$ Hepatocellular carcinoma

\begin{abstract}
Background/Aims: Our recent study indicated that the serum microcystin-LR (MC-LR) level is positively linked to the risk of human hepatocellular carcinoma (HCC). Gankyrin is overexpressed in cancers and mediates oncogenesis; however, whether MC-LR induces tumor formation and the role of gankyrin in this process is unclear. Methods: We induced malignant transformation of L02 liver cells via 35 passages with exposure to 1, 10, or 100 nM MC-LR. Wound healing, plate and soft agar colony counts, and nude mice tumor formation were used to evaluate the tumorigenic phenotype of MC-LR-treated cells. Silencing gankyrin was used to confirm its function. We established a 35-week MC-LR exposure rat model by twice weekly intraperitoneal injection with $10 \mu \mathrm{g} / \mathrm{kg}$ body weight. In addition, $96 \mathrm{HCC}$ patients were tested for tumor tissue gankyrin expression and serum MC-LR levels. Results: Chronic low-dose MC-LR exposure increased proliferation, mobility, clone and tumor formation abilities of L02 cells as a result of gankyrin activation, while silencing gankyrin inhibited the carcinogenic phenotype of MC-LR-treated cells. MC-LR also induced neoplastic liver lesions in Sprague-Dawley rats due to up-regulated gankyrin. Furthermore, a trend of increased gankyrin was observed in humans exposed to MC-LR. Conclusion: These results suggest that MC-LR induces hepatocarcinogenesis in vitro and in vivo by increasing gankyrin levels, providing new insight into MC-LR carcinogenicity studies.

\section{Introduction}

Microcystins comprise the largest class of cyanotoxins that contaminate human drinking water, making them a worldwide environmental concern as global warming increases. Microcystin-LR (MC-LR), considered to be the most potent and abundant 


\section{Cellular Physiology Cell Physiol Biochem 2018;49:1420-1430

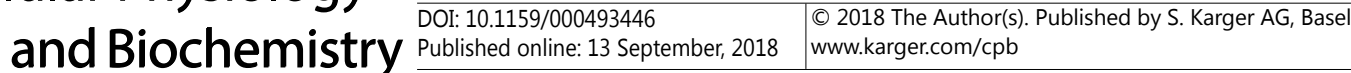 \\ He et al.: Microcystin-LR Induces Carcinogenesis via Increased Gankyrin}

cyanobacterial toxin, induces cytotoxicity and tumor promotion mainly by increasing ROS formation and inhibiting PP1 and PP2A (serine/threonine protein phosphatases 1 and $2 \mathrm{~A}$ ), leading to hyperphosphorylation of several proteins involved in maintaining cell homeostasis [1]. MC-LR influences the structure and function of the liver, kidney, brain, testicle, and thyroid gland in animals [2-6]. In addition, we have previously reported that MC-LR impaired liver and kidney function in humans [7, 8].

The main target organ of MC-LR is the liver, and several animal experiments have clearly demonstrated the tumor-promoting ability of MC-LR in this organ. However, controversy surrounds whether MC-LR can induce tumor formation. Although chronic low-dose MC-LR exposure did not increase the risk of developing tumors or induce tumors in animals [9], some data has indicated its tumorigenicity in cell lines $[10,11]$ and our recent population study demonstrated a significant positive correlation between serum MC-LR levels and risk of hepatocellular carcinoma (HCC) [12]. Hence, the objective of this study was to elucidate the effects and mechanisms of MC-LR in tumor inducement in vitro and in vivo.

Gankyrin, a 26S proteasome non-ATPase regulatory subunit encoded by PSMD10, is dramatically increased in several cancers, including HCC $[13,14]$. It is recognized as a key oncoprotein in the development of cancer due to its degradation effect on P53 $[15,16]$. Gankyrin facilitates HCC development by mediating the de-differentiation of hepatocyte cells via HNF $4 \alpha$ down-regulation [17] and accelerates liver cancer metastasis via activation of phosphoinositol 3-kinase/AKT/hypoxia-inducible factor-1 $\alpha$ pathways [18]. In addition, gankyrin promotes the malignant transformation of liver fibrosis to hepatocarcinoma via the Ras-related C3 botulinum toxin substrate 1/c-jun N-terminal kinase pathway [19]. Interfering with gankyrin expression may serve as a novel strategy for HCC prevention and treatment $[20,21]$.

In this study, chronic MC-LR exposure induced the malignant transformation of L02 cells as a result of increased gankyrin levels. Then, by establishing a rat model through continuous exposure to MC-LR for 35 weeks, we confirmed the relationship between MCLR and gankyrin in vivo. Furthermore, we analyzed the association of the internal exposure level of MC-LR and gankyrin expression in patients with HCC. Together, these results indicate that MC-LR can activate the oncogene gankyrin to induce malignant transformation, in addition to providing new information for intervention and carcinogenicity studies of MCLR.

\section{Materials and Methods}

\section{Cell treatment}

We obtained the L02 cells from the Department of Hepatobiliary Surgery (Southwest Hospital of the Army Medical University, Chongqing, China). This cell line consists of normal human liver cell lines and is suitable to study the process of hepatocarcinogenesis from a normal to malignant state. Cells were continuously exposed to $0.1 \%$ DMSO (Sigma-Aldrich, St. Louis, MO, USA) as control cells or different doses $(0,1,10$, or $100 \mathrm{nM}$ ) of MC-LR (Express, Inc. Beijing, China) for 5, 15, 25, and 35 passages (named $\mathrm{P} 5, \mathrm{P} 15, \mathrm{P} 25$, and P35, respectively). The cells were cultured at $37^{\circ} \mathrm{C}$ and with $5 \% \mathrm{CO}_{2}$ on Dulbecco's modified Eagle media (DMEM) containing 10\% fetal bovine serum (FBS) and 1\% penicillin-streptomycin.

\section{Cell proliferation assay}

Cells treated with MC-LR or DMSO were grown for 12, 24, 48, and $72 \mathrm{~h}$ in 96-well plates with 5000 cells per well at $37^{\circ} \mathrm{C}$ with $5 \% \mathrm{CO}_{2}$. The cells were then incubated with $10 \mu \mathrm{l}$ of Cell Counting Kit 8 (CCK8) reagent (Dojindo, Japan) for $1 \mathrm{~h}$ and measured at an absorbance of $450 \mathrm{~nm}$ using a Multiskan MK3 instrument (Thermo Fisher Scientific, Waltham, MA, USA).

\section{Scratch experiment}

This procedure has been described previously [22]. Briefly, cells were cultured with DMEM containing $10 \% \mathrm{FBS}$ and $1 \%$ penicillin-streptomycin at $37^{\circ} \mathrm{C}$ with $5 \% \mathrm{CO}_{2}$. After the cells grew to $100 \%$ integration, a vertical wound was made in cells plated in 6-well plates using a sterilized 10- $\mu$ l pipette tip. We then removed the detached cells using PBS and added medium. We observed the wound after 12 and $24 \mathrm{~h}$ at $20 \times$ magnification using a microscope and Image Pro Plus version 6.0 software to assess wound closure. 


\section{Cellular Physiology Cell Physiol Biochem 2018;49:1420-1430 and Biochemistry Published online: 13 September, 2018 \begin{tabular}{l|l} 
DOI: 10.1159/000493446 2018 The Author(s). Published by S. Karger AG, Basel \\
www.karger.com/cpb
\end{tabular} \\ He et al.: Microcystin-LR Induces Carcinogenesis via Increased Gankyrin}

\section{Plate cloning analysis}

Cells $\left(1 \times 10^{3}\right)$ were cultured in 6-well plates for 15 days and the medium was changed every four days. Cells were fixed for $10 \mathrm{~min}$ with paraformaldehyde and then Giemsa-stained for $10 \mathrm{~min}$. Visible cloning was observed and evaluated.

\section{Soft agar assay}

This method has been previously described [23]. Briefly, soft agar with two layers was prepared in each well of the 12 -well plates. The base layer contained $1 \mathrm{ml}$ of $1.3 \%$ agar, and $2 \times 10^{3}$ cells in medium containing $0.35 \%$ agar were plated above it and incubated at $37^{\circ} \mathrm{C}$ for 2 weeks. Colony formation $(>0.5$ $\mathrm{mm}$ in diameter) was counted using an inverted microscope at $20 \times$ magnification, and the total number of colonies on the entire plate was counted. The relative colony count was calculated using the colony count on each plate/cells plated.

\section{$B A L B / c$ nude mice tumor formation}

The Institutional Animal Care and Use Committee of the Army Medical University approved all animal treatments. We purchased BALB/c nude mice (aged 4 weeks, male) from the Experimental Animal Center of the Army Medical University. Each group contained three nude mice. Each mouse received $2 \times$ $10^{6} \mathrm{~L} 02$ cells for the control group and MC-LR-treated groups, which were injected into the left armpit of the mouse. Observations were made every two days for 28 days and the length and width of each tumor was measured.

\section{Gene silencing and plasmid transfection}

MC-LR-treated L02 cells (100 nM) were transfected using Plve1761vctor lentiviral small interfering RNA (siRNA) particles (Sunbio Medical Biotechnology Co., Ltd, Shanghai, China) containing an siRNA sequence specific for gankyrin (AAGACACUGAGGGUAACACTT) or the control siRNA sequence (TTCTCCGAACGTGTCACGT) at 15 TU/cell. Cells were cultured with 10\% FBS DMEM containing polybrene $(2 \mu \mathrm{g} / \mathrm{ml})$ for $1 \mathrm{~h}$ at $37^{\circ} \mathrm{C}$. We selected cells expressing siRNAs using $4 \mu \mathrm{g} / \mathrm{ml}$ puromycin for 2 weeks. The interference efficiency of gankyrin was evaluated via quantitative real-time PCR (qRT-PCR) and western blot.

\section{Animal model}

Sprague-Dawley (SD) rats (aged 6 weeks, male) were obtained from the Army Medical University Experimental Animal Center and raised in a germ-free animal house. We randomly divided 54 SD rats into two groups, the control group and MC-LR-treated group (each group containing 27 rats). Rats were injected intraperitoneally twice a week with $2 \mathrm{mg}$ DMSO/kg body weight (bw) for the control group and $10 \mu \mathrm{g} / \mathrm{kg}$ bw MC-LR for the MC-LR-treated group at 7 weeks of age and randomly euthanized after treatment for 10, 20, or 35 weeks. Liver sections were stained with hematoxylin and eosin (HE) or immunohistochemical (IHC) and the remaining tissues were stored at $-80^{\circ} \mathrm{C}$ for subsequent analysis.

\section{HCC patient tumor tissues and MC-LR exposure test}

The Ethics Committee of the Army Medical University approved this study and all participants signed informed consent forms. We randomly selected 96 patients with HCC from our previous case-control study [12]. Liver tumor tissues were collected following surgery on patients diagnosed with HCC from Army Medical University hospitals. Serum MC-LR concentrations were measured using enzyme-linked immunosorbent assay kits (Beacon Analytical Systems, Inc., Saco, Maine, USA). The 96 participants were divided into two groups based on their median MC-LR exposure levels, termed the high-MC-LR exposure group and low-MC-LR exposure group.

\section{qRT-PCR analysis}

Total RNA was extracted using trizol (Sigma-Aldrich) according to the manufacturer's protocol. Two micrograms RNA was used for cDNA synthesis using the protocol of the RNA reverse transcription kit (Takara Bio, Inc., Otsu, Japan). Two microliters cDNA, $10 \mu \mathrm{l} \mathrm{mix,} 1 \mu \mathrm{l}$ forward primer, $1 \mu \mathrm{l}$ reverse primer, and $6 \mu \mathrm{H}_{2} \mathrm{O}_{2}$ were mixed and underwent stage 1: one cycle of $95^{\circ} \mathrm{C}$ for $10 \mathrm{~min}$; stage 2: 40 cycles of $95^{\circ} \mathrm{C}$ for $15 \mathrm{~s}$ and $60^{\circ} \mathrm{C}$ for $20 \mathrm{~s}$; and stage 3: melt curve analysis. The reaction was performed using the SYBR Green PCR Kit (Takara Bio, Inc.) and an Applied Biosystems CXF-96 PCR instrument (Bio-rad, California, USA). The primers were purchased from the Shanghai Shenggong Company and the homo primers were: GAPDH forward: CACTCCTCTACACTTAGCCTGTGA, reverse: TAACCTTCCACCATTCTCTTGA. Gankyrin forward: ACATCGCTCAGACACCATG, reverse: TGTAGTTGAGGTCAATGAAGGG. The rat primers: 


\section{Cellular Physiology Cell Physiol Biochem 2018;49:1420-1430

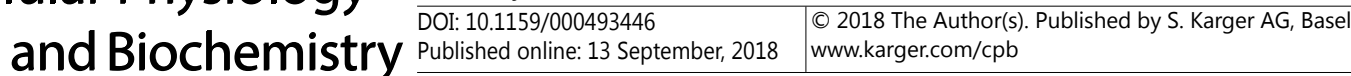 \\ He et al.: Microcystin-LR Induces Carcinogenesis via Increased Gankyrin}

GAPDH forward: ACATCGCTCAGACACCATG, reverse: TGTAGTTGAGGTCAATGAAGGG. Gankyrin forward: GGGTGTGTGTCTAACATAATGG, reverse: AATGCTGTTCTGTCCTG. The relative expression of each tested gene was calculated using the $2^{-\Delta \Delta \mathrm{CT}}$ method.

Western blot

The procedure was conducted as previously described [24]. The total protein of cells or liver tissues was extracted using RIPA lysis buffer (Beyotime, Shanghai, China) according to the manufacturer's protocol. Protein concentrations were quantified using the BCA Kit (Beyotime). Protein (30-50 $\mu \mathrm{g})$ was separated on a $12 \%$ sodium dodecyl sulfate-polyacrylamide gel and transferred to polyvinylidene fluoride membranes (Micron Separations, Westborough, MA, USA). Proteins were blocked using a block kit (Beyotime), overnight cultured with gankyrin rabbit IgG antibody (Abcam, Cambridge, MA, USA; catalog no. ab182576; dilution: $1: 1000$ ) at $4^{\circ} \mathrm{C}$, and with a secondary antibody for $30 \mathrm{~min}$. The immunoreactive proteins were detected using an enhanced chemiluminescence system (Amersham-Pharmacia Biotech, Piscataway, NJ, USA) and subsequent autoradiography.

\section{IHC staining}

Each liver section was deparaffinized for $2 \mathrm{~h}$ at $65^{\circ} \mathrm{C}$, subjected to xylene 3 times for $10 \mathrm{~min}$, and then $100 \%, 90 \%$, and $70 \%$ alcoholic dehydration each for $5 \mathrm{~min}$; the inactivation of peroxidases was achieved using $3 \% \mathrm{H}_{2} \mathrm{O}_{2}$ for $10 \mathrm{~min}$, washing 3 times for $15 \mathrm{~min}$ each time with PBS, antigen retrieval for $20 \mathrm{~min}$ at $98^{\circ} \mathrm{C}$, and finally blocked for $1 \mathrm{~h}$ at $37^{\circ} \mathrm{C}$. Sections were cultured with ankyrin rabbit IgG antibody (Abcam; catalog no. ab182576; dilution: 1:250) or GST-P rabbit IgG antibody (Abcam; catalog no. ab138491; dilution: $1: 250$ ) overnight at $4^{\circ} \mathrm{C}$, with secondary antibodies for $1 \mathrm{~h}$ at $37^{\circ} \mathrm{C}$, and then diaminobenzidine for $3 \mathrm{~min}$ and hematoxylin counterstained for $2 \mathrm{~min}$. Glutathione S-transferase placental form (GST-p) analysis was performed according to our previous study, and the area and number of positive foci in the entire liver section were recorded using a microscope. Gankyrin-positive cells were counted in five random fields to calculate the average positive cell rate.

\section{Statistical analysis}

SPSS software 19 was used and data shows the mean \pm standard deviation. Homoscedasticity was verified when using a parametric test. The independent t-test was used to detect differences between two groups (e.g., differences inGST-p foci or the ratio in the control and MC-LR-treated groups). Oneway analysis of variance (ANOVA) and least significant difference (LSD) analysis were used to detect differences among three or more groups. Correlation between the MC-LR exposure level and gankyrin expression in HCC patients were compared using a Pearson $\chi 2$ test and any difference was statistically significant at $p<0.05$.

\section{Results}

MC-LR promotes proliferation, mobility, and colony formation of L02 cells

Results from the CCK-8 assay showed that MC-LR significantly promoted cell proliferation in a time- and dose-dependent manner (Fig. 1A). Wound-healing assay results indicated that MC-LR increased cell mobility. L02 cells moved faster when exposed to $100 \mathrm{nM}$ MC-LR compared with 1 and $10 \mathrm{nM}$ MC-LR exposure (Fig. 1B). Data from the plate colony-formation assay revealed a dose-dependent increase in colony numbers in the MC-LR-exposed group (Fig. 1C). In comparison with the control, the colony formation in soft agar was significantly elevated in MC-LR-treated cells (Fig. 1D).

\section{MC-LR induced xenograft formation in nude mice}

To demonstrate that MC-LR induced the malignant transformation of L02 cells in vivo, we injected cells treated with MC-LR for 35 passages into the left armpit of nude mice and observed tumor formation for 28 days. Tumor xenografts were observed in mice inoculated with 1, 10, or $100 \mathrm{nM}$ MC-LR-treated L02 cells, whereas no tumor formation was observed in the control group (Fig. 2A). Increased tumor volumes and weights indicated that MC-LR promoted tumor growth in nude mice (Fig. 2B, 2C). The above findings suggest that L02 cells underwent malignant transformation due to MC-LR in vivo. 
Gankyrin expression gradually increased in MC-LR-transformed L02 cells

L02 cells exposed to 1,10 , or $100 \mathrm{nM} \mathrm{MC-LR}$ for $5,15,25$, or 35 passages were tested for gankyrin expression. qRT-PCR analysis revealed both a time- and dose-dependent enhancement of gankyrin expression in MC-LR-transformed L02 cells, and the non-treated group indicated cells without any treatment (Fig. 3A). Similarly, western blot results indicated that gankyrin protein expression increased in a time-dependent manner in 100 nM MC-LR-treated cells (Fig. 3B). In addition, immunohistochemical staining showed that gankyrin expression in xenografts of nude mice increased dose-dependently (Fig. 3C). These results suggest that gankyrin expression gradually increased during the process of MC-LR inducing the malignant transformation of L02 cells.

Silencing gankyrin restrained the MC-LR carcinogenic effect on LO2 cells

qRT-PCR and western blot demonstrated the inhibition of gankyrin in transformed cells (Fig. 4A, 4B). CCK-8 assays showed that silencing gankyrin expression significantly inhibited transformed cell proliferation (Fig. 4C). Wound-healing assays indicated that the speed of movement toward the wound was significantly lower for the siGankyrin cells than for the siControl cells (Fig. 4D). As shown in Fig. 4E, colony-formation assays revealed less colony formation in the siGankyrin cells than found in the siControl cells. Taken together, these results reveal that gankyrin inhibition significantly attenuated the malignant transformation of L02 cells induced by MC-LR.

Fig. 1. MC-LR promotes proliferation, mobility, and cloning formation of L02 cells. (A) Proliferation of L02 cells exposed to MC-LR $(0,1,10$, and $100 \mathrm{nM}$ ) for $12,24,48$, or $72 \mathrm{~h}$. (B) The mobility of L02 cells treated with MC-LR. (C) Clone formation of MC-LRtreated L02 cells on plates. (D) Anchorage-independent growth of clones of MC-LRtreated L02 cells in soft agar. Experiments were performed three times independently, and data are presented as the mean \pm standard deviation; one-way ANOVA LSD was used for statistical analysis; ${ }^{*} \mathrm{p}<0.05$ compared with control.
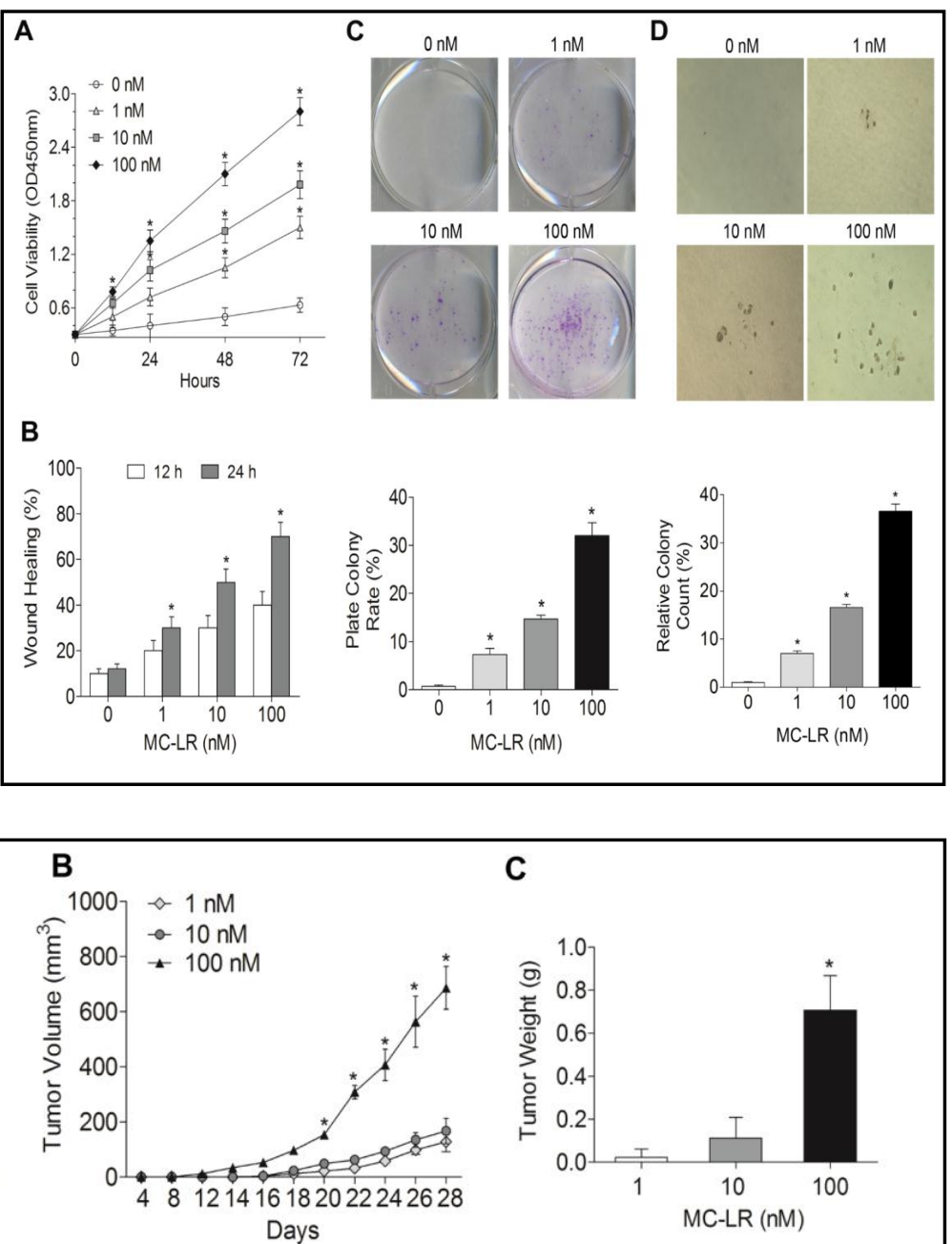

C

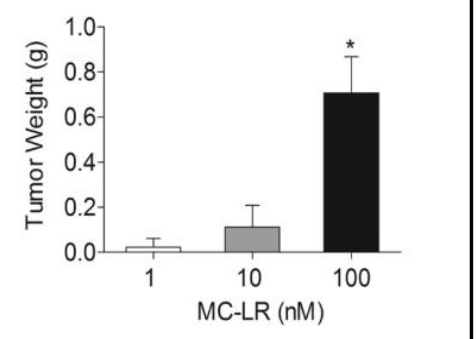

Fig. 2. MC-LR induced tumor formation in nude mice. (A) Tumor xenograft formation of nude mice in each group, $n=3$, respectively. (B, C) Nude mice tumor volumes and weights. One-way ANOVA LSD was used; ${ }^{*} \mathrm{p}<0.05$ compared with the other groups. 
Fig. 3. MC-LR increased gankyrin expression during L02 cell transformation. (A) qRT-PCR analysis showing gankyrin expression in the MC-LR-treatment group, whereas the non-treated group indicated cells without any treatment. (B) Western blot results revealing gankyrin expression in $100 \mathrm{nM}$ MC-LR-exposed cells in 15, 25, and 35 passages. (C) IHC staining showing gankyrin-positive staining in xenograft tumor tissues of BALB/c nude mice inoculated with MC-LR-treated L02 cells $(\times 200)$. GAPDH was used as the internal control for qRT-PCR, and the results are expressed as mean \pm standard error of fold changes from three independent experiments. One-way ANOVA LSD was used; *p<0.05 compared with control.

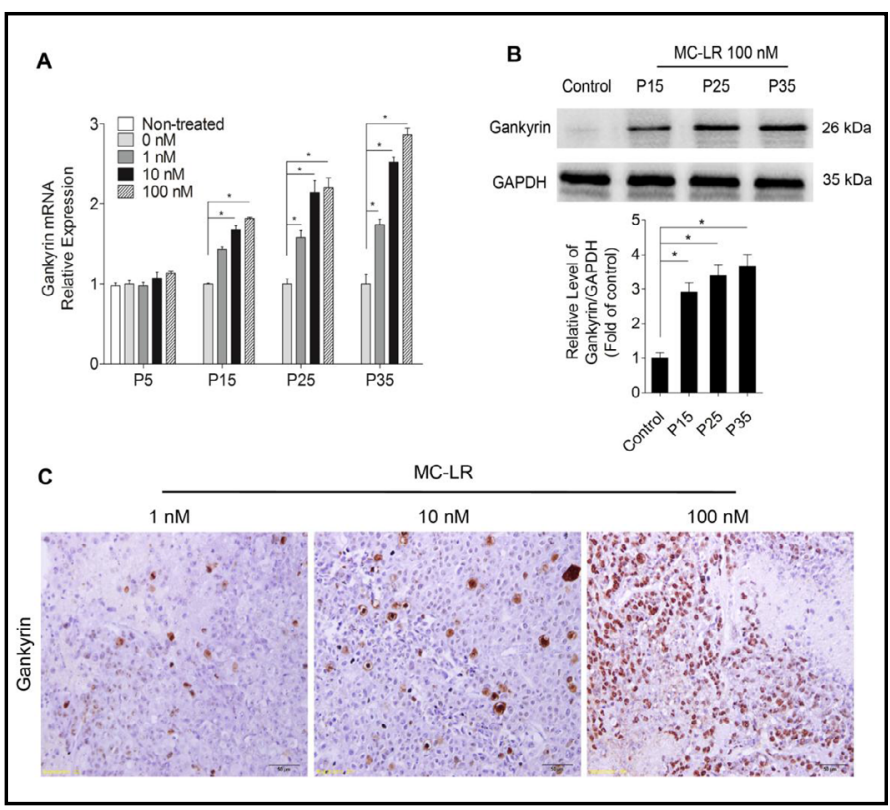

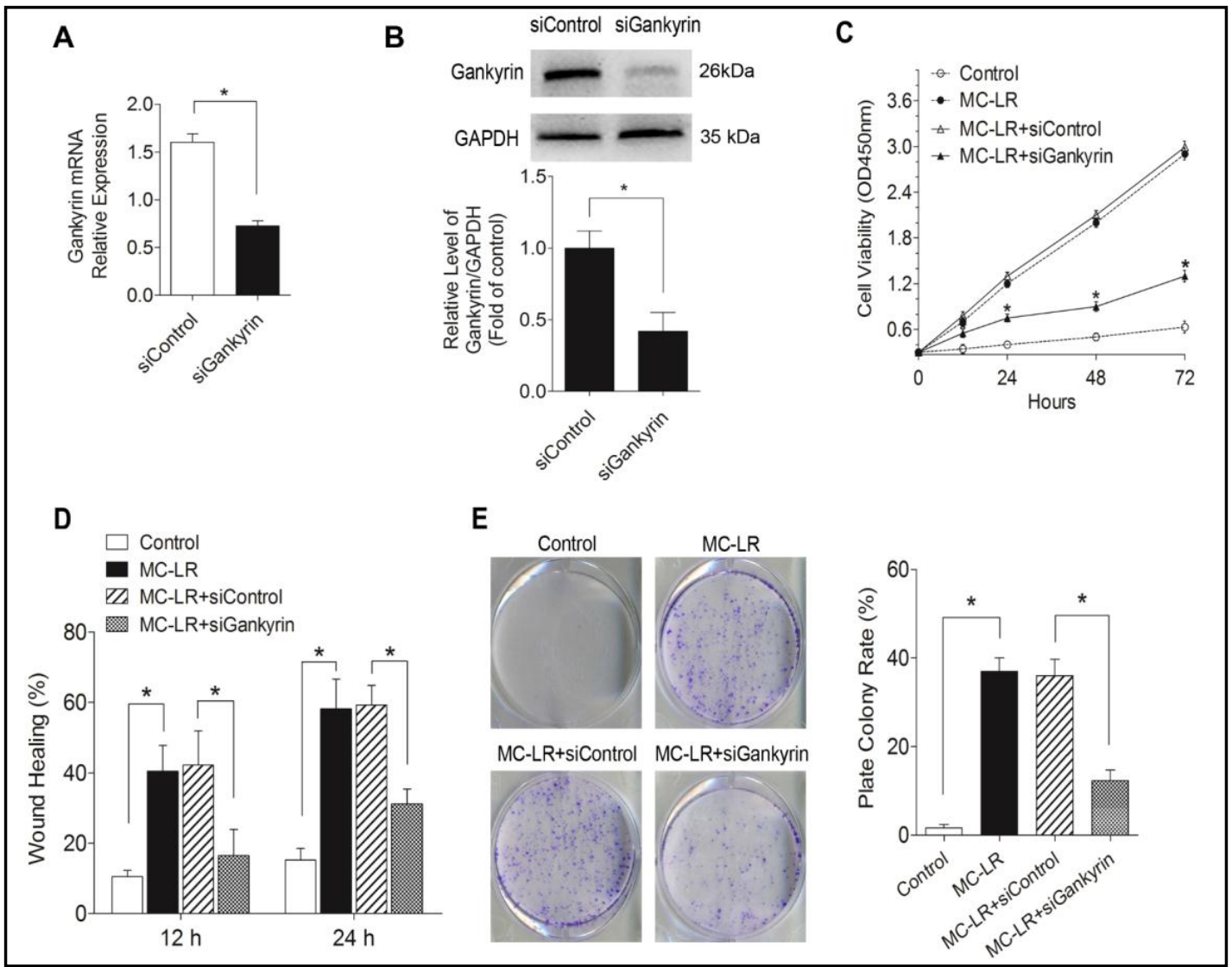

Fig. 4. Silencing of gankyrin inhibited proliferation, mobility, and colony formation of MC-LR-treated L02 cells. (A, B) qRT-PCR and western blot assay showing gankyrin expression in L02 cells. (C) CCK-8 test revealing the proliferation of L02 cells treated with MC-LR after silencing gankyrin; $\mathrm{p}<0.05$ compared with MC-LR + siControl. (D) Wound-healing assay results indicating the mobility of L02 cells treated using MC-LR with gankyrin knockdown. (E) Colony formation in the siGankyrin group and siControl group. Independent t-test was used; ${ }^{*} \mathrm{p}<0.05$. 
Fig. 5. MC-LR induced liver neoplastic lesions in SD rats. (A) HE staining, electron microscope, and glutathione S-transferase (GST) IHC staining of livers from control and MC-LR-treated SD rats $(\times 200)$. (B) Bar chart revealing GST-positive foci numbers and the area of livers from rats treated for 10, 20, and 35 weeks in the control and MC-LR groups, $n=27$, respectively. Independent t-test was used; ${ }^{*} \mathrm{p}<0.05$.
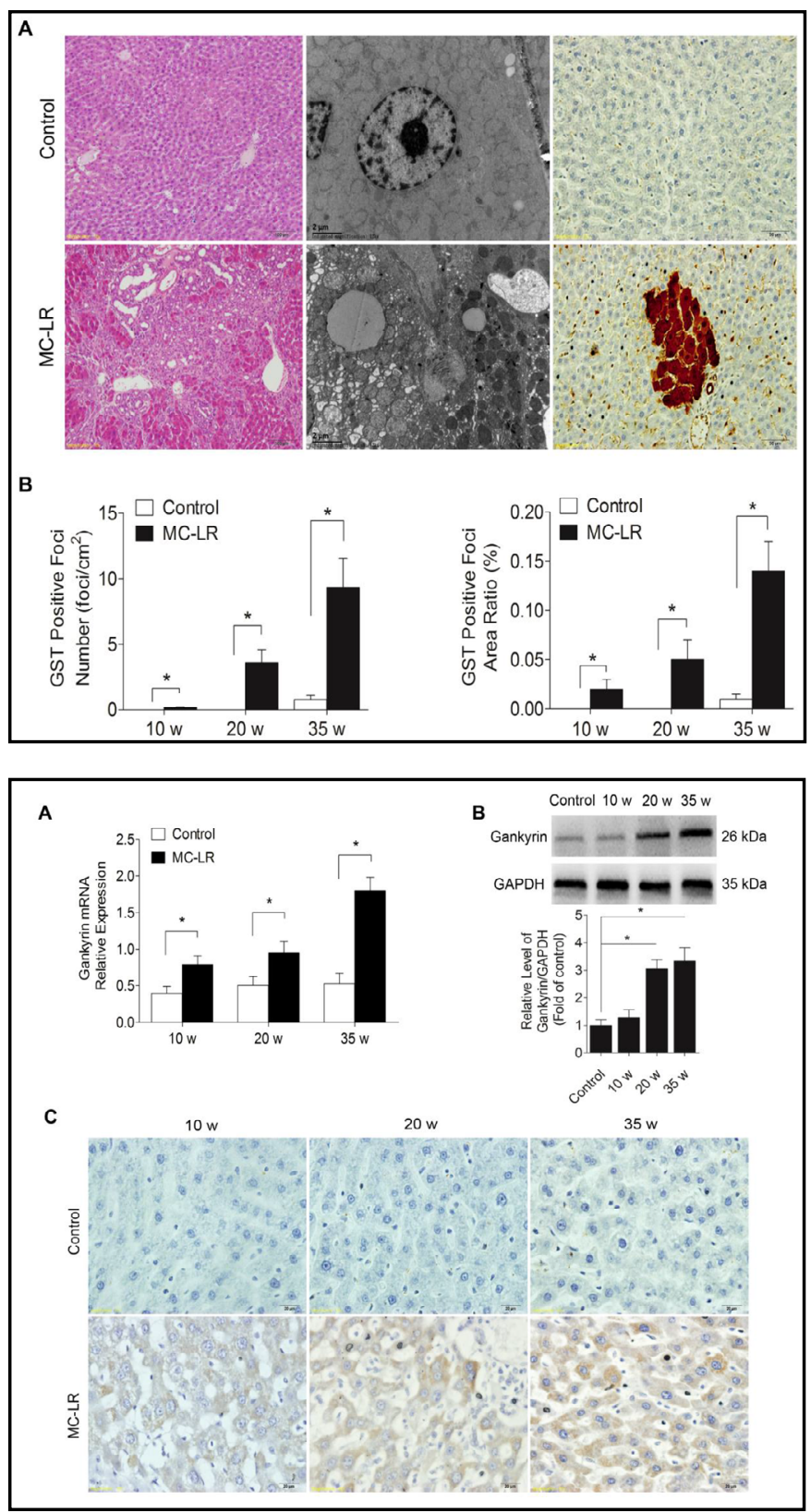

Fig. 6. MC-LR increased gankyrin expression during neoplastic lesion formation in SD rats. (A) Gankyrin mRNA expression in SD rats treated with MC-LR. (B) Western blot analysis showing gankyrin expression in MC-LRtreated rats. (C) IHC staining revealing gankyrin-positive cells (mainly in the cytoplasm in liver neoplastic lesion non-tumor tissue) in the MC-LR group $(\times 400)$. One-way ANOVA LSD was used; $* \mathrm{p}<0.05$.
$M C$-LR increased neoplastic lesions in $S D$ rats

We also established a rat model via treatment with MC-LR for 35 weeks to confirm that gankyrin expression increased in MC-LR induced hepatocarcinogenesis in vivo. Fig. 5A shows the HE staining, electron microscope, and glutathione S-transferase (GST) IHC staining images, respectively. Liver necrosis and proliferation nodules were observed in the MC-LR group by HE staining. Electron microscope results revealed increased lipid droplets and
Table 1. Basic information for the study participants and their MC-LR exposure levels. MC-LR: microcystin-LR; Low MC-LR: low MC-LR exposure group; High MC-LR: high MC-LR exposure group; HBV: hepatitis B virus

\begin{tabular}{|c|c|c|c|}
\hline & $\begin{array}{l}\text { Low MC-LR } \\
\qquad(\mathrm{n}=48)\end{array}$ & $\begin{array}{l}\text { High MC-LR } \\
\qquad(n=48)\end{array}$ & $\mathrm{p}$ value \\
\hline \multirow[b]{2}{*}{ Sex } & 37 & 42 & \multirow[b]{2}{*}{0.285} \\
\hline & 11 & & \\
\hline Age & $49.50 \pm 10.79$ & $49.77 \pm 8.65$ & 0.892 \\
\hline MC-LR (ng/ml) & $0.45 \pm 0.10$ & $0.89 \pm 0.19$ & 0.000 \\
\hline HBV infection positive (n) & 47 & 45 & 0.617 \\
\hline
\end{tabular}




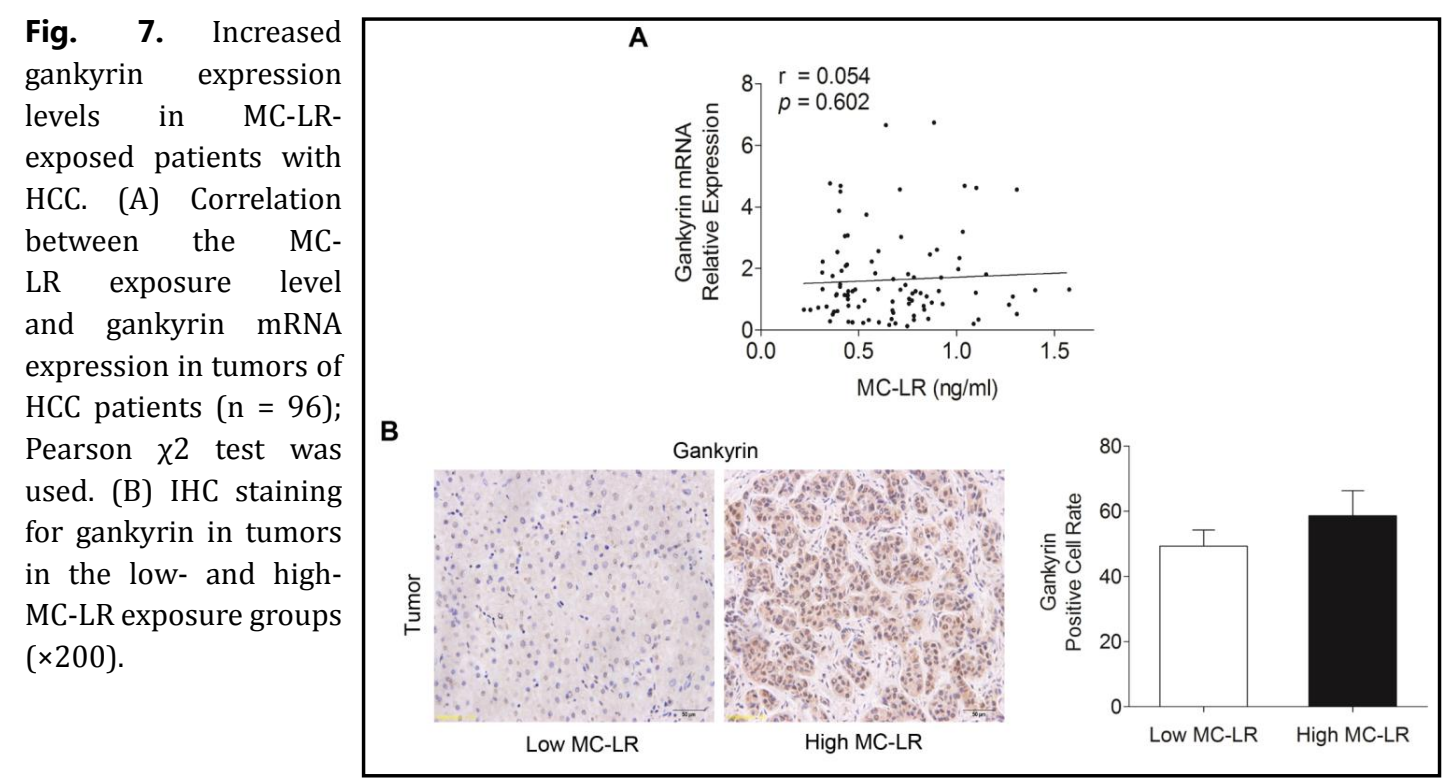

fiber in liver cells of MC-LR-treated rats. GST-positive foci have been extensively used as an indication of liver neoplastic lesion and terminal markers for hepatocarcinoma [25]. Immunohistochemical staining showed GST-positive foci in the MC-LR-treated group, and the numbers and areas in the liver of each rat were quantified, as shown in Fig. 5B, indicating a time-dependent increase of GST by MC-LR.

\section{Gankyrin expression was up-regulated in MC-LR induced liver neoplastic lesions in SD} rats

We evaluated the dynamic changes of gankyrin in SD rats exposed to MC-LR for 10, 20, and 35 weeks, and qRT-PCR showed that gankyrin gene expression significantly increased (Fig. 6A). Western blot results indicated that gankyrin expression significantly increased during the process of MC-LR induced liver neoplastic lesion formation (Fig. 6B). Similarly, IHC results revealed a gradual increase of the gankyrin-positive foci in MC-LR-treated rats (Fig. 6C). These results indicate that gankyrin levels increased in MC-LR induced liver neoplastic lesions of SD rats.

Gankyrin expression levels were elevated in high-MC-LR exposure patients with HCC

To determine the relationship between MC-LR exposure and gankyrin expression, we collected 96 paired tumor tissues and blood samples from patients diagnosed with HCC. We divided them into the low- or high-MC-LR exposure groups according to their median MC-LR exposure level. Basic patient information and MC-LR exposure levels are described in Table 1. It can be seen that sex, age, and number positive for hepatitis B virus infection were not significantly different between the low-MC-LR and high-MC-LR exposure group, which indicates that the baseline characteristics of these two groups are consistent. A positive, though not significant, correlation was found between the gankyrin expression level and the MC-LR exposure level in tumors (Fig. 7A). In addition, as shown in Fig. 7B, IHC analysis also showed an increasing trend of gankyrin expression in the MC-LR highexposure patients.

\section{Discussion}

This is the first study to demonstrate that MC-LR can induce malignant transformation in normal human liver cells and neoplastic lesion formation in SD rats via the inducement of a key oncogene, gankyrin. Furthermore, it reveals a positive correlation between serum MC-LR levels and gankyrin expression in HCC patients. 


\section{Cellular Physiology Cell Physiol Biochem 2018;49:1420-1430 \begin{tabular}{l|l} 
DOl: 10.1159/000493446 & $\begin{array}{l}\text { O 2018 The Author(s). Published by S. Karger AG, Basel } \\
\text { www.karger.com/cpb }\end{array}$
\end{tabular} \\ He et al.: Microcystin-LR Induces Carcinogenesis via Increased Gankyrin}

MC-LR is a potent tumor-promoting agent that contaminates human drinking water. However, whether it can initiate carcinogenesis via inducing key cancer-related oncogenes remains to be elucidated. Only a few studies indicate that MC-LR can malignantly transform normal human cells. For example, colorectal crypt cells are reportedly transformed by microcystin through Akt-MAPK activation [11]. MC-LR induced carcinogenicity in human liver cells WRL-68 accompanied changes to microRNA [10]. In our study, MC-LR promoted proliferation, mobility, and cloning formation of L02 cells. Furthermore, L02 cells exposed to MC-LR for 35 passages induced tumor formation in nude mice. These findings indicate that MC-LR induces malignant transformation in L02 cells.

The constitutive activation of oncogenes and inactivation of anti-oncogenes is typical during cancer development. Oncogenes such as $c$-fos and $c$-myc were activated by MC-LR in Wistar rats [26], whereas MC-LR inactivates p53 to promote cell proliferation via Akt activation [27]. In HepG 2 cells, MC-LR significantly de-regulates p53 to interfere with DNA repair [28]. Gankyrin is a key oncogene that contributes to the development of HCC. In this study, both gene and protein expression of gankyrin were found to gradually increase during MC-LR induced transformation of L02 cells. Silencing gankyrin expression in cells inhibited the proliferation, mobility, and colony-forming abilities of MC-LR-transformed L02 cells, which indicates a vital role of gankyrin in MC-LR-transformed cells. In tumor tissue, gankyrin is expressed in both the nucleus and cytoplasm but is predominantly nuclear; however, in non-tumor tissue, it is mainly expressed in the cytoplasm and rarely in the nucleus [29]. In our study, gankyrin was expressed mainly in the nuclei in the liver tumor tissues of HCC patients, while in the livers of MC-LR-treated rats, gankyrin was expressed in the cytoplasm. This indicates that MC-LR does not induce tumor formation in rats. However, we demonstrated that MC-LR can induce neoplastic lesions in rat livers, meaning that the mechanism of MC-LR inducing gankyrin activation requires further study. We infer that increased ROS formation, c-myc expression and Akt-MAPK pathway activation may explain how MC-LR mediates increased gankyrin levels. ROS formation has been reported to contribute to gankyrin activation $[30,31]$. In addition, $c-m y c$, as an oncogene induced by MC-LR, was also demonstrated to be a transcriptional activator of gankyrin [32]. MC-LR is reported to transform colorectal crypt cells via Akt-MAPK activation [11]. Furthermore, MAPK activation contributes to increased HURP (hepatoma up-regulated protein), which leads to the accumulation of gankyrin by reducing its ubiquitination [33].

The evidence supporting tumor initiation by MC-LR in animals is insufficient. However, several two-stage carcinogenesis animal experiments showed that MC-LR enhanced GST expression in diethylnitrosamine (DEN) or aflatoxin-B1 (AFB1) initiated rats, demonstrating the tumor-promoting activity of MC-LR [34]. In this study, MC-LR alone increased the numbers and areas of GST and induced liver neoplastic alterations in SD rats as a result of the up-regulation of gankyrin.

Epidemiological studies, although limited, have indicated increased incidence of liver cancers associated with chronic MC-LR exposure [35, 36]. The relationship between MCLR internal exposure levels and gankyrin expression levels in human HCC is not clear; however, we found a positive correlation between MC-LR exposure level and gankyrin expression in HCC patients. Gankyrin protein expression in these patients, detected by IHC, agreed with the gene-expression results. However, more samples should be included to confirm a significant relationship between them.

\section{Conclusion}

Our results suggest that MC-LR induces malignant transformation in human liver cells and neoplastic lesions in SD rats, which involves an increase in gankyrin levels, indicating that MC-LR can activate oncogenes to induce carcinogenesis. Further, we found a positive correlation between serum MC-LR levels and gankyrin expression in patients with HCC. These findings provide evidence for the potential carcinogenicity of MC-LR and shed light on gankyrin as a potential clinical target for anti-cancer therapy. 


\section{Cellular Physiology Cell Physiol Biochem 2018;49:1420-1430 and Biochemistry Published online: 13 September, 2018 \begin{tabular}{l|l} 
DOI: 10.1159/000493446 2018 The Author(s). Published by S. Karger AG, Basel \\
www.karger.com/cpb
\end{tabular} \\ He et al.: Microcystin-LR Induces Carcinogenesis via Increased Gankyrin}

\section{Acknowledgements}

This work was supported by the National Natural Science Foundation of China (Grant No. 81230064, 81302407, and 81402647) and the Natural Science Foundation of Chongqing (Grant No. cstc2014jcyjA00049).

\section{Disclosure Statement}

The authors indicate no potential conflicts of interest.

\section{References}

1 Liu J, Sun Y: The role of PP2A-associated proteins and signal pathways in microcystin-LR toxicity. Toxicol Lett 2015;236:1-7.

2 Chen L, Chen J, Zhang X, Xie P: A review of reproductive toxicity of microcystins. J Hazard Mater 2016;301:381-399.

- 3 Hu Y, Chen J, Fan H, Xie P, He J: A review of neurotoxicity of microcystins. Environ Sci Pollut Res Int 2016;23:7211-7219.

4 Leal Ade C, Soares Mdo C: [Hepatotoxicity of the microcystin cyanotoxin]. Rev Soc Bras Med Trop 2004;37 Suppl 2:84-89.

5 Wu Q, Yan W, Liu C, Li L, Yu L, Zhao S, Li G: Microcystin-LR exposure induces developmental neurotoxicity in zebrafish embryo. Environ Pollut 2016;213:793-800.

6 Zhao Y, Xue Q, Su X, Xie L, Yan Y, Steinman AD: Microcystin-LR induced thyroid dysfunction and metabolic disorders in mice. Toxicology 2015;328:135-141.

7 Li Y, Chen JA, Zhao Q, Pu C, Qiu Z, Zhang R, Shu W: A cross-sectional investigation of chronic exposure to microcystin in relationship to childhood liver damage in the Three Gorges Reservoir Region, China. Environ Health Perspect 2011;119:1483-1488.

-8 Lin H, Liu W, Zeng H, Pu C, Zhang R, Qiu Z, Chen JA, Wang L, Tan Y, Zheng C, Yang X, Tian Y, Huang Y, Luo J, Luo Y, Feng X, Xiao G, Feng L, Li H, Wang F, Yuan C, et al.: Determination of Environmental Exposure to Microcystin and Aflatoxin as a Risk for Renal Function Based on 5493 Rural People in Southwest China. Environ Sci Technol 2016;50:5346-5356.

-9 Labine M, Minuk GY: Long-term, low-dose exposure to microcystin toxin does not increase the risk of liver tumor development or growth in mice. Hepatol Res 2015;45:683-692.

-10 Xu L, Qin W, Zhang H, Wang Y, Dou H, Yu D, Ding Y, Yang L, Wang Y: Alterations in microRNA expression linked to microcystin-LR-induced tumorigenicity in human WRL-68 Cells. Mutat Res 2012;743:75-82.

11 Zhu Y, Zhong X, Zheng S, Ge Z, Du Q, Zhang S: Transformation of immortalized colorectal crypt cells by microcystin involving constitutive activation of Akt and MAPK cascade. Carcinogenesis 2005;26:12071214.

12 Zheng C, Zeng H, Lin H, Wang J, Feng X, Qiu Z, Chen JA, Luo J, Luo Y, Huang Y, Wang L, Liu W, Tan Y, Xu A, Yao Y, Shu W: Serum microcystin levels positively linked with risk of hepatocellular carcinoma: A casecontrol study in southwest China. Hepatology 2017;66:1519-1528.

13 Jing H, Zhang G, Meng L, Meng Q Mo H, Tai Y: Gradually elevated expression of Gankyrin during human hepatocarcinogenesis and its clinicopathological significance. Sci Rep 2014;4:5503.

14 Liu Y, Xu J, Jiang M, Ni L, Chen Y, Ling Y: Association between functional PSMD10 Rs111638916 variant regulated by MiR-505 and gastric cancer risk in a Chinese population. Cell Physiol Biochem 2015;37:10101017.

15 Higashitsuji H, Itoh K, Nagao T, Dawson S, Nonoguchi K, Kido T, Mayer RJ, Arii S, Fujita J: Reduced stability of retinoblastoma protein by gankyrin, an oncogenic ankyrin-repeat protein overexpressed in hepatomas. Nat Med 2000;6:96-99.

16 Tan L, Fu XY, Liu SQ Li HH, Hong Y, Wu MC, Wang HY: Expression of p28GANK and its correlation with RB in human hepatocellular carcinoma. Liver Int 2005;25:667-676.

17 Sun W, Ding J, Wu K, Ning BF, Wen W, Sun HY, Han T, Huang L, Dong LW, Yang W, Deng X, Li Z, Wu MC, Feng GS, Xie WF, Wang HY: Gankyrin-mediated dedifferentiation facilitates the tumorigenicity of rat hepatocytes and hepatoma cells. Hepatology 2011;54:1259-1272. 


\section{Cellular Physiology Cell Physiol Biochem 2018;49:1420-1430 \begin{tabular}{l|l|l} 
and Biochemistry $10.1159 / 000493446$ & $\begin{array}{l}\text { C) } 2018 \text { The Author(s). Published by S. Karger AG, Basel } \\
\text { www.karger.com/cpb }\end{array}$ \\
\hline
\end{tabular}

18 Fu J, Chen Y, Cao J, Luo T, Qian YW, Yang W, Ren YB, Su B, Cao GW, Yang Y, Yan YQ Shen F, Wu MC, Feng GS, Wang HY: p28GANK overexpression accelerates hepatocellular carcinoma invasiveness and metastasis via phosphoinositol 3-kinase/AKT/hypoxia-inducible factor-1alpha pathways. Hepatology 2011;53:181-192.

19 Zhao X, Fu J, Xu A, Yu L, Zhu J, Dai R, Su B, Luo T, Li N, Qin W, Wang B, Jiang J, Li S, Chen Y, Wang H: Gankyrin drives malignant transformation of chronic liver damage-mediated fibrosis via the Rac1/JNK pathway. Cell Death Dis 2015;6:e1751.

20 Wang C, Cheng L: Gankyrin as a potential therapeutic target for cancer. Invest New Drugs 2017;35:655661.

21 Zamani P, Matbou Riahi M, Momtazi-Borojeni AA, Jamialahmadi K: Gankyrin: a novel promising therapeutic target for hepatocellular carcinoma. Artif Cells Nanomed Biotechnol 2018;49:1301-1313.

-22 Chen J, Chang H, Peng X, Gu Y, Yi L, Zhang Q Zhu J, Mi M: 3, 6-dihydroxyflavone suppresses the epithelialmesenchymal transition in breast cancer cells by inhibiting the Notch signaling pathway. Sci Rep 2016;6:28858.

23 Ba Q, Li J, Huang C, Qiu H, Li J, Chu R, Zhang W, Xie D, Wu Y, Wang H: Effects of benzo [a]pyrene exposure on human hepatocellular carcinoma cell angiogenesis, metastasis, and NF-kappaB signaling. Environ Health Perspect 2015;123:246-254.

24 Xu C, Chen JA, Qiu Z, Zhao Q Luo J, Yang L, Zeng H, Huang Y, Zhang L, Cao J, Shu W: Ovotoxicity and PPARmediated aromatase downregulation in female Sprague-Dawley rats following combined oral exposure to benzo [a]pyrene and di-(2-ethylhexyl) phthalate. Toxicol Lett 2010;199:323-332.

-25 Tatematsu M, Tsuda H, Shirai T, Masui T, Ito N: Placental Glutathione S-Transferase (GST-P) as a New Marker for Hepatocarcinogenesis: In vivo Short-Term Screening for Hepatocarcinogens. Toxicol Pathol 1987;15:60-68.

26 Li H, Xie P, Li G, Hao L, Xiong Q: In vivo study on the effects of microcystin extracts on the expression profiles of proto-oncogenes (c-fos, c-jun and c-myc) in liver, kidney and testis of male Wistar rats injected i.v. with toxins. Toxicon 2009;53:169-175.

27 Takumi S, Komatsu M, Furukawa T, Ikeda R, Sumizawa T, Akenaga H, Maeda Y, Aoyama K, Arizono K, Ando S, Takeuchi T: p53 Plays an important role in cell fate determination after exposure to microcystin-LR. Environ Health Perspect 2010;118:1292-1298.

28 Zegura B, Gajski G, Straser A, Garaj-Vrhovac V, Filipic M: Microcystin-LR induced DNA damage in human peripheral blood lymphocytes. Mutat Res 2011;726:116-122.

29 Luo T, Fu J, Xu A, Su B, Ren Y, Li N, Zhu J, Zhao X, Dai R, Cao J, Wang B, Qin W, Jiang J, Li J, Wu M, Feng G, Chen Y, Wang H: PSMD10/gankyrin induces autophagy to promote tumor progression through cytoplasmic interaction with ATG7 and nuclear transactivation of ATG7 expression. Autophagy 2016;12:1355-1371.

-30 Sakurai T, Kudo M, Umemura A, He G, Elsharkawy AM, Seki E, Karin M: p38alpha inhibits liver fibrogenesis and consequent hepatocarcinogenesis by curtailing accumulation of reactive oxygen species. Cancer Res 2013;73:215-224.

31 Yang C, Tan YX, Yang GZ, Zhang J, Pan YF, Liu C, Fu J, Chen Y, Ding ZW, Dong LW, Wang HY: Gankyrin has an antioxidative role through the feedback regulation of Nrf2 in hepatocellular carcinoma. J Exp Med 2016;213:859-875.

32 Dong LW, Yang GZ, Pan YF, Chen Y, Tan YX, Dai RY, Ren YB, Fu J, Wang HY: The oncoprotein p28GANK establishes a positive feedback loop in beta-catenin signaling. Cell Res 2011;21:1248-1261.

-33 Chao CC: Inhibition of apoptosis by oncogenic hepatitis B virus X protein: Implications for the treatment of hepatocellular carcinoma. World J Hepatol 2016;8:1061-1066.

34 Zegura B: An Overview of the Mechanisms of Microcystin-LR Genotoxicity and Potential Carcinogenicity. Mini Rev Med Chem 2016;16:1042-1062.

35 Svircev Z, Drobac D, Tokodi N, Luzanin Z, Munjas AM, Nikolin B, Vuleta D, Meriluoto J: Epidemiology of cancers in Serbia and possible connection with cyanobacterial blooms. J Environ Sci Health C Environ Carcinog Ecotoxicol Rev 2014;32:319-337.

-36 Ueno Y, Nagata S, Tsutsumi T, Hasegawa A, Watanabe MF, Park HD, Chen GC, Chen G, Yu SZ: Detection of microcystins, a blue-green algal hepatotoxin, in drinking water sampled in Haimen and Fusui, endemic areas of primary liver cancer in China, by highly sensitive immunoassay. Carcinogenesis 1996;17:13171321. 